\title{
Transient Stability Analysis during an Improved Coupling Procedure for an Induction Generator Based Wind Generation System to the Grid
}

\author{
Soulaymen Kammoun*, Amal Marrekchi, Souhir Sallem, Mohamed Ben Ali Kammoun \\ Commande des Machines Electriques et Réseauxde Puissance (CMERP), University of Sfax, Sfax, Tunisia \\ Email: ‘soulaymen.kammoun@gmail.com, amal.marrekchi@gmail.com, souhirsallem@gmail.com, \\ mbakammoun@gmail.com
}

Received 20 May 2014; revised 18 June 2014; accepted 3 July 2014

Copyright @ 2014 by authors and Scientific Research Publishing Inc.

This work is licensed under the Creative Commons Attribution International License (CC BY).

http://creativecommons.org/licenses/by/4.0/

(c) (i) Open Access

\begin{abstract}
For fixed speed wind turbines, the connection of its squirrel cage induction generator (SCIG) to the grid leads to inrush current which can reach an average of 2 p.u. up to 2.5 p.u. in higher wind speed even by using a soft starter. We propose in this paper a new soft starting of squirrel cage induction generator based wind turbine connected to the grid. Our strategy overcomes such transient instability problems and pinpoints rapidly synchronous speed regardless the wind speed acting on pitch angle. The proposed strategy ensures at least $50 \%$ reduction of inrush current and $18 \%$ gain of WTG starting time. A state model of the system is given including the wind turbine model and the SCIG model in the synchronous reference frame. Simulation results are analysed and compared to the classic coupling procedure.
\end{abstract}

Keywords

Wind Energy, Pitch Control, Squirrel Cage Induction Generator, Transient Stability, Soft Starting

\section{Introduction}

Recently, there has been a world-wide interest in wind energy since it is becoming the world's fastest growing energy source with an average growth over the past 7 years of $26 \%$ and a $12 \%$ foreseeable penetration of global electricity demand by 2020 [1].

"Corresponding author.

How to cite this paper: Kammoun, S., Marrekchi, A., Sallem, S. and Kammoun, M.B.A. (2014) Transient Stability Analysis during an Improved Coupling Procedure for an Induction Generator Based Wind Generation System to the Grid. International Journal of Modern Nonlinear Theory and Application, 3, 77-87. http://dx.doi.org/10.4236/ijmnta.2014.33010 
Several wind turbine generator (WTG) concepts have been developed during the last years. The main purpose of research on these concepts has been especially about maximizing energy capture, minimizing cost, and improving energy produced quality [2]-[6].

Among these various concepts, the squirrel cage induction generator (SCIG) based WTG. Known also as the fixed speed, pitch controlled WTG.

The WTGs with fixed speed are also consisted of a large number of compensating capacitors, operating on an internal electrical network in order to provide reactive power requirements of SCIGs (for a wind farm) and improving the power factor of the energy fed to the grid.

A lot of recent research focused on modelling/simulation of this WTG type [7]-[11]. Modelling and simulation allow researchers to predict unwanted phenomena not only for transient state but also for permanent state of the system.

One important phenomenon is the important inrush current into the SCIG during connection to the grid, as has traditionally been the most important feature of soft-starters [12], and this, in order to improve the overall transient stability. Nevertheless, this transient stability can meet further improvement by ensuring a stable system even before coupling. However, traditional coupling methods consist on starting the wind turbine, when the wind speed allows it, and connecting to the grid in an acceleration phase whenever the speed reaches approximately the synchronism.

Yet there is a dearth of information about the coupling moment in order to optimize transient stability. Therefore, the present study offers an improved starting/coupling procedure, where WTG is started unloaded near the synchronism speed in a steady state.

The remainder of this paper is divided into four sections. Section 2 gives the description and a modelling of the system components. In Section 3, we develop steps of the starting-coupling strategy. Simulation results of this method are presented and discussed in Section 4. A conclusion of this study is presented in the last section.

\section{System Description and Modelling}

The studied WTG concept is known as the Danish concept [13]. It consists of a turbine rotor coupled to a soft-started grid-connected SCIG through a gearbox. Figure 1 illustrates a single line representation of the last.

\subsection{Wind Turbine Model}

The functioning of a wind turbine can be described by modeling the rotational mechanism. Applying the actuator disk theory [1], the rotor model provides the mechanical torque extracted from the wind by Equation (1):

$$
T_{m}=P_{m} \frac{R}{v_{\text {wind }} G}
$$

where $R(\mathrm{~m})$ is the rotor disk radius, $v_{\text {wind }}(\mathrm{m} / \mathrm{s})$ is the wind speed, $G$ is the gearbox ratio and $P_{m}(\mathrm{~W})$ is the mechanical power which given by Equation (2)

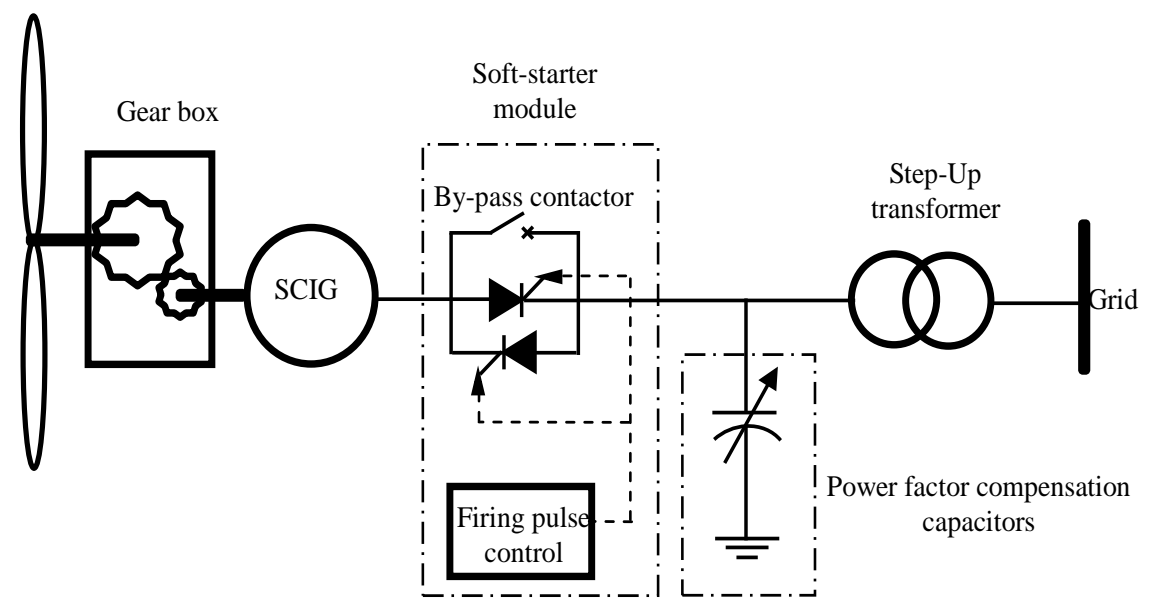

Figure 1. Single line diagram of a WTG equiped with a SCIG. 


$$
P_{m}=0,5 C_{p} \rho \pi R^{2} v_{\text {wind }}^{3}
$$

where $\rho\left(\mathrm{Kg} / \mathrm{m}^{3}\right)$ is the air density and $C_{p}(\lambda, \beta)$ is the power coefficient (Beltz coefficient) which is a function of the tip speed ratio $\lambda$ (given by Equation (3)) and the blade pitch angle $\beta$ and given by Equation (4).

$$
\begin{gathered}
\lambda=\frac{\omega R}{v_{\text {wind }}} \\
C_{p}(\lambda, \beta)=C_{1}\left(\frac{C_{2}}{\lambda_{i}}-C_{3} \beta-C_{4}\right) \mathrm{e}^{-\frac{C_{5}}{\lambda_{i}}}+C_{6} \lambda
\end{gathered}
$$

$\omega$ is the turbine speed (rd/s), $C_{i}\{i=1, \cdots, 6\}$ are given in Table 1 and $\lambda_{i}$ is given by Equation (5)

$$
\frac{1}{\lambda_{i}}=\frac{1}{\lambda+0.08 \beta}-\frac{0.035}{\beta^{3}+1}
$$

\subsection{SCIG Model}

Adopting generator convention and choosing a reference linked to the stator pulsation then the synchronous frame, mathematical model of the SCIG [14]-[16] is given by Equations (6)-(8).

- Electrical equations

$$
\left\{\begin{array}{l}
\frac{\mathrm{d} \bar{\Psi}_{s n}}{\mathrm{~d} t}=-R_{s} \bar{i}_{s n}-\bar{v}_{s n}-j \omega_{0} \bar{\Psi}_{s n} \\
\frac{\mathrm{d} \bar{\Psi}_{r n}^{\prime}}{\mathrm{d} t}=-R_{r} \bar{i}_{r n}^{\prime}+j\left(\omega_{r}-\omega_{0}\right) \bar{\Psi}_{r n}^{\prime}
\end{array}\right.
$$

- Magnetic equations

$$
\left\{\begin{array}{l}
\bar{\Psi}_{s n}=L_{s} \bar{i}_{s n}+M \bar{i}_{r n}^{\prime} \\
\bar{\Psi}_{r n}^{\prime}=L_{r} \bar{i}_{r n}^{\prime}+M \bar{i}_{s n}
\end{array}\right.
$$

- Mechanical equation

$$
\frac{\mathrm{d} \omega_{r}}{\mathrm{~d} t}=\frac{p}{J}\left(T_{m}+\frac{3}{2} p M \operatorname{Imag}\left(\overline{\bar{i}}_{\mathrm{s}} \overline{\bar{i}}_{s n}^{*}\right)\right)
$$

\subsection{Soft Starter Model}

A soft-starter is basically an AC/AC converter, where for firing angles smaller than $\frac{5 \pi}{6}$ rad, the relationship between the firing angle and the controlled voltage is non-linear and depends additionally on the power factor of the connected element. The power factor depends in turn in this controlled voltage and its variation and other generator characteristics [17]. This non-linearity makes it not feasible to obtain the supplied voltage versus firing angle characteristic in the state model. A continuous model of the last where relation between RMS output and input voltages for a delayed current (case of the SCIG) is given by Equation (9) [18]:

Table 1. $C_{i}$ coefficients values.

\begin{tabular}{ccccccc}
\hline$C_{i}$ & $C_{1}$ & $C_{2}$ & $C_{3}$ & $C_{4}$ & $C_{5}$ & $C_{6}$ \\
\hline Value & 0.5176 & 116 & 0.4 & 5 & 21 & 0.0068 \\
\hline
\end{tabular}




$$
\left\{\begin{array}{l}
\left.\frac{V_{\text {out }_{R M S}}}{V_{\text {in }_{R M S}}}\right|_{\Psi>\varphi}=\sqrt{\frac{1}{\pi}\left(\beta-\Psi-\frac{1}{2} \sin (2 \beta)-\sin (2 \Psi)\right)} \\
\left.\frac{V_{\text {out }_{R M S}}}{V_{\text {in }_{R M S}}}\right|_{\Psi<\varphi}=1
\end{array}\right.
$$

where $\Psi$ is the firing angle of thyristors, $\varphi$ is the current delay relative to the voltage and $\beta=\pi+\varphi$.

Figure 2 shows $\frac{V_{\text {out RuS }_{\text {R }}}}{V_{\text {in }_{\text {RUS }}}}$ versus firing angle for a $20^{\circ}$ delayed current.

\section{Starting Method}

\subsection{Data Analyses}

Traditionally, whenever the wind speed exceeds the cut-in speed, WTGs are started unloaded. The pitch angle used, issued from a regulation loop, is generated in order to give maximum mechanical power.

Using Equations (1), (2) and only the mechanical Equation of the SCIG (8) (No connection with the grid means no electrical equations) gives us the WTG unloaded model. Figure 3 and Figure 4 illustrate respectively the evolution of the mechanical torque and the rotor speed of a given wind speed and pitch angle.

It is clear in Figure 4 that the rotor speed reaches its steady state when the mechanical torque in Figure 3 returns to zero.

Analyzing the WTG unloaded functioning; it is obvious that pitch angle affects directly the mechanical torque (Figure 5) then the rotor speed (Figure 6).

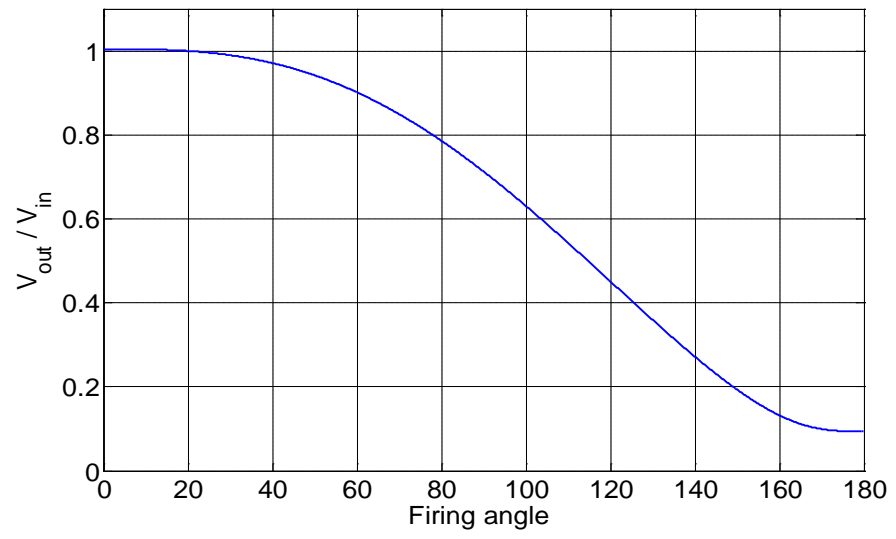

Figure 2. Soft-starter layout for a $20^{\circ}$ delayed current.

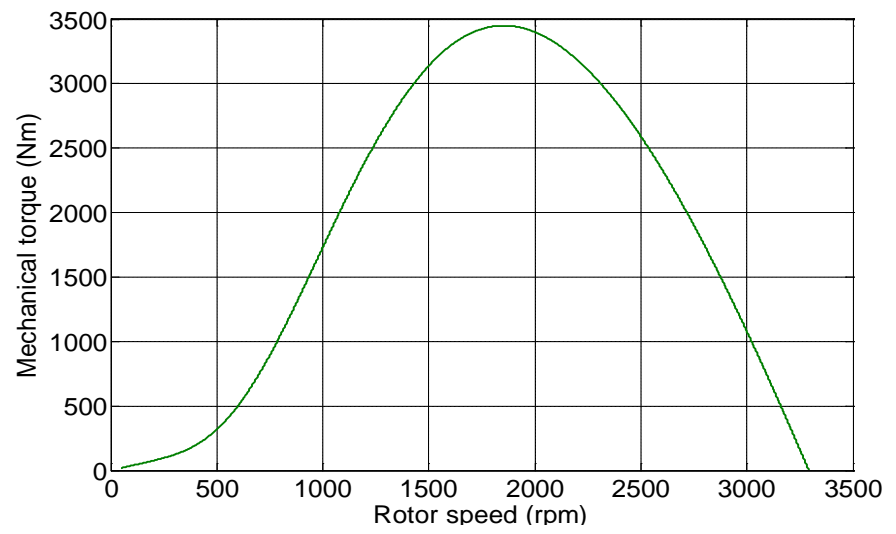

Figure 3. Evolution of the unloaded WTG's mechanical torque. 


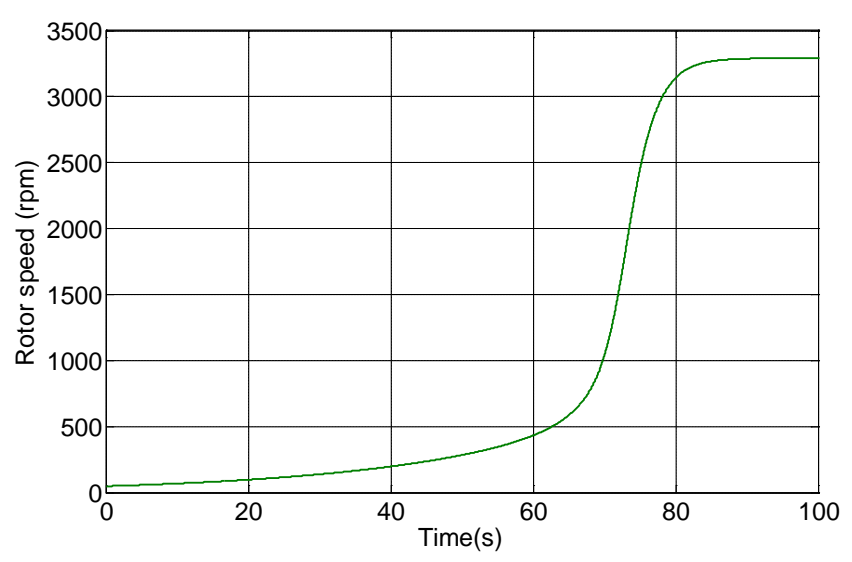

Figure 4. Evolution of the unloaded WTG's rotor speed.

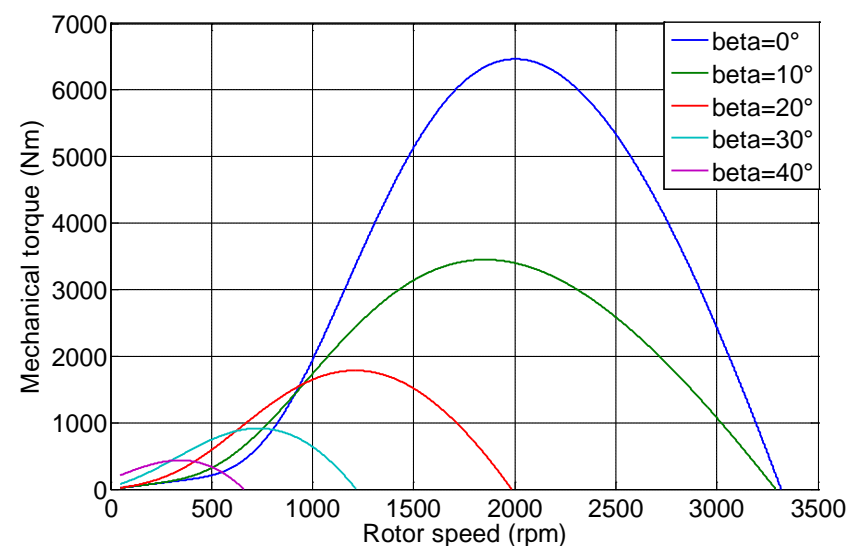

Figure 5. Evolution of the unloaded WTG's mechanical torque for different pitch angles.

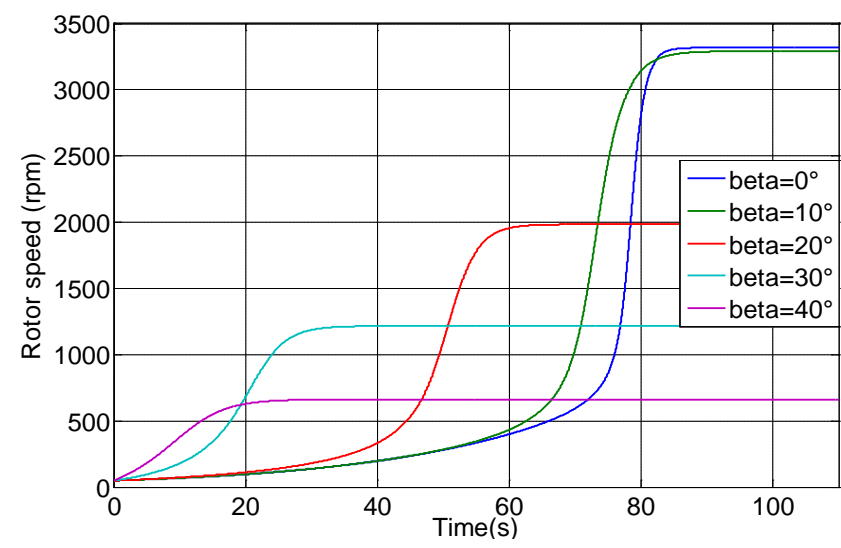

Figure 6. Evolution of the unloaded WTG's rotor speed for different pitch angles.

Therefore, we can deduce that for each wind speed exists a specific pitch angle where the rotor speed steady state is the closest to the synchronism speed.

\subsection{Transient Stability Improvement}

In order to improve transient stability of the wind generation system by avoiding inrush currents, we propose to 
verify two specific conditions before connecting to the grid:

- A zero mechanical torque;

- The closest rotor speed value just above the synchronism speed.

The need of these two conditions comes from the fact that the difference between the two torques (mechanical and electromagnetic) is zero just in the coupling moment.

That way, no big variation in the rotor speed neither in the torques could happen throughout the soft-starting operation, therefore a stable connection is guaranteed.

From Figure 5 and Figure 6, these two conditions are verified together only after the speed reaches its steady state for a specific wind speed and pitch angle.

\subsection{Starting Pitch Angle Determination}

The present study comes to propose an algorithm with the ability of determining the corresponding starting pitch angle. This algorithm is set up to work off-line based in WTG characteristics.

Beyond cut-in speed and till cut-off speed a look up table is generated with corresponding starting pitch angle for the given wind speed interval $\left(\beta_{\text {start }}=f\left(V_{\text {wind }}\right)\right)$ within pitch angle variation $(\Delta \beta)$ limits.

Figure 7 gives the flowchart of the algorithm giving starting pitch angel. Figure 8 gives the breakpoints issued from the algorithm of the proposed starting pitch angle versus wind speed.

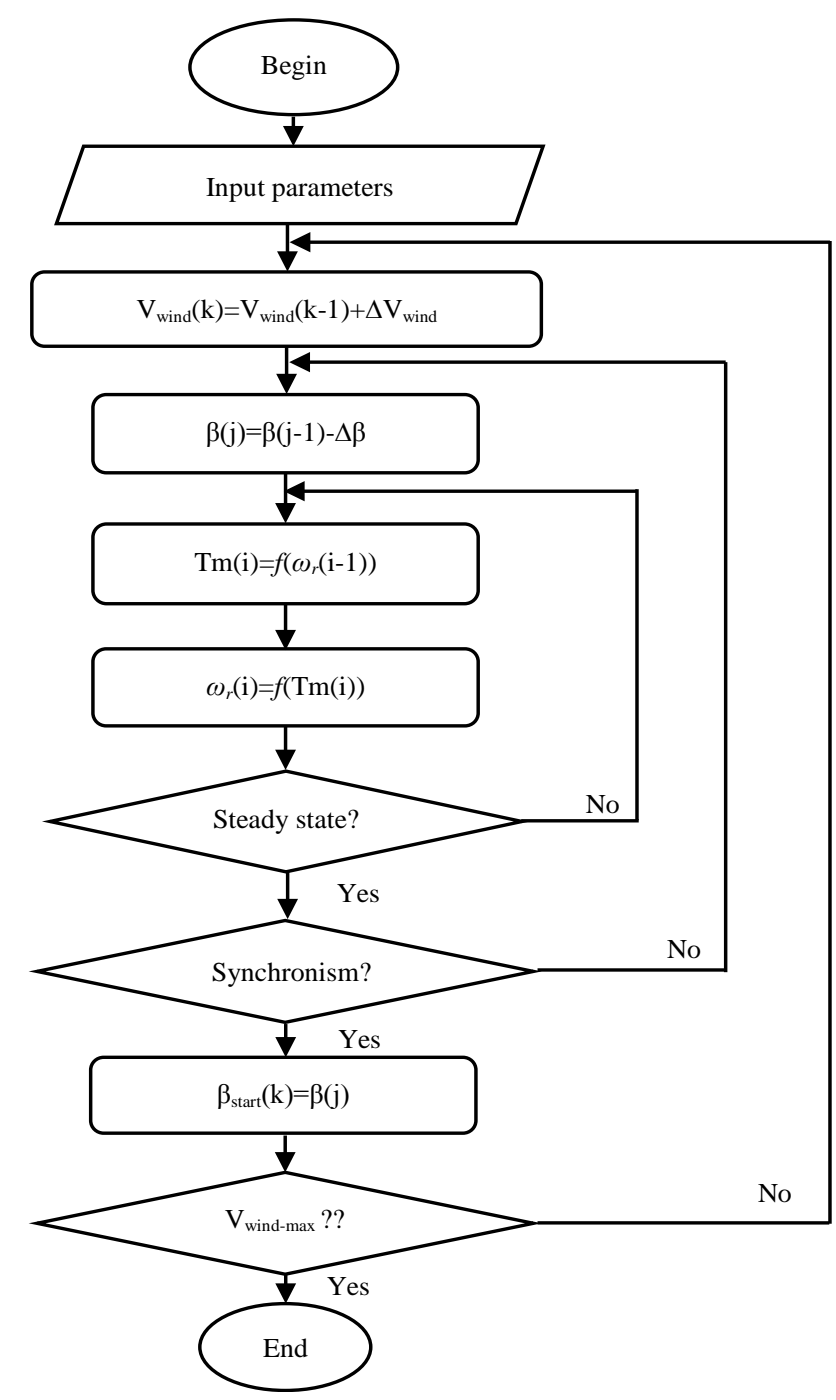

Figure 7. Starting pitch angle determination flowchart. 


\subsection{Proposed Procedure}

On this paper, a starting procedure divided into four steps is proposed:

- Starting the WTG with the starting pitch angle issued from the look up table corresponding to the available wind.

- Once steady state reached, WTG is switched on the grid throughout the soft starter by decreasing firing angles of thyristors within a specific law.

- After soft starting procedure is completed, each line triacs is by-passed by a mechanical contactor.

- Pitch angle is modified again in order to extract maximum power from the wind.

\section{Results and Discussion}

To evince the efficiency and performance of the proposed starting procedure, we compare it to the classic one. The classical procedure consists of starting the wind turbine unloaded with the available wind and a pitch angle giving maximum power corresponding to this wind speed. Once synchronism reached, the WTG is coupled to the grid through the soft-starter. Firing angle control is done on a way to reduce inrush current to the maximum.

Considering a $10 \mathrm{~m} / \mathrm{s}$ wind speed, the following simulation results was based on a WT and SCIG which characteristics, token from [19], are summarized in Table 2.

The starting pitch angle issued from the algorithm given in Figure 7 is 25 degrees for the given wind speed to be brought back after the connection to 2 degrees (pitch angle giving maximum mechanical power).

Figure 9 and Figure 10 show respectively mechanical and electromagnetic torques and speed on the rotor shaft of the SCIG.

It is obvious by these figures that our strategy offers more stability when connecting the SCIG to the grid. Moreover, the pitch angle pinpoints the speed to the corresponding synchronous speed faster than the classical strategy.

This prevent the electromagnetic torque exceeding and thus generated current which never cross 1 p.u. in

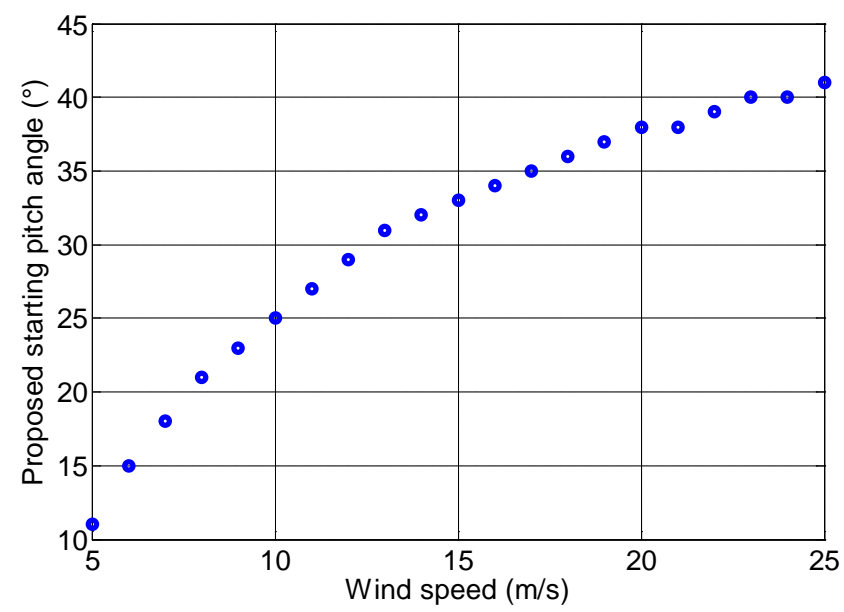

Figure 8. Starting pitch angle versus wind speed.

Table 2. WTG characteristics.

\begin{tabular}{|c|c|c|c|c|c|c|c|c|c|}
\hline \multirow[b]{2}{*}{ Parametre } & \multicolumn{9}{|c|}{ Squirrel cage induction generator } \\
\hline & $P$ & $U$ & $f$ & $R_{s}$ & $R_{r}$ & $L_{s s}=L_{s r}^{\prime}$ & $L_{m s}$ & $J$ & $p$ \\
\hline \multirow[t]{2}{*}{ Value } & $1.5 \mathrm{MW}$ & $690 \mathrm{~V}$ & $50 \mathrm{~Hz}$ & $8.9 \mathrm{~m} \Omega$ & $13.7 \mathrm{~m} \Omega$ & $12.53 \mathrm{mH}$ & $12.67 \mathrm{mH}$ & $100 \mathrm{Kg} \cdot \mathrm{m}^{2}$ & 2 \\
\hline & \multicolumn{9}{|c|}{ Wind turbine } \\
\hline Parametre & \multicolumn{3}{|c|}{$\rho$} & \multicolumn{3}{|c|}{$G$} & \multicolumn{3}{|c|}{$R$} \\
\hline Value & \multicolumn{3}{|c|}{$1.22 \mathrm{Kg} / \mathrm{m}^{3}$} & \multicolumn{3}{|c|}{35} & \multicolumn{3}{|c|}{$13.5 \mathrm{~m}$} \\
\hline
\end{tabular}




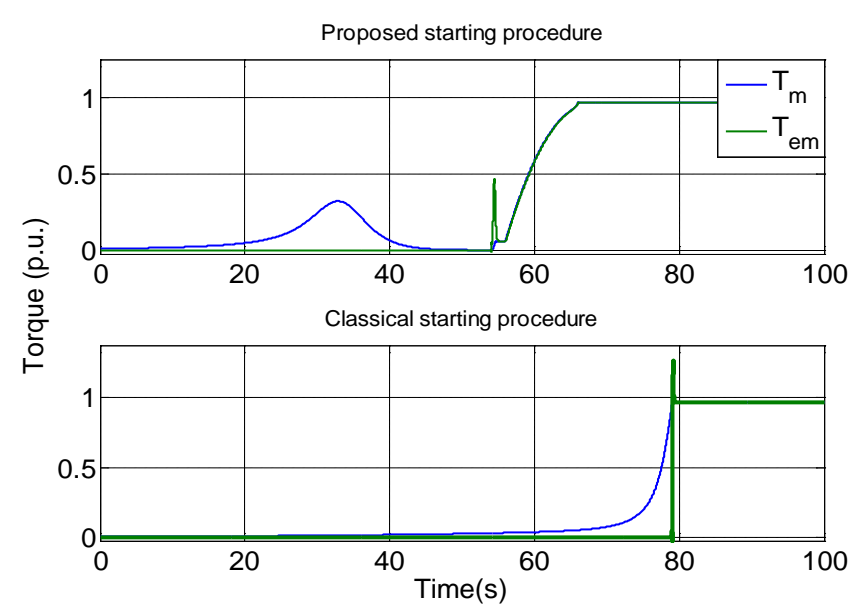

Figure 9. Evolution of WTG torques.

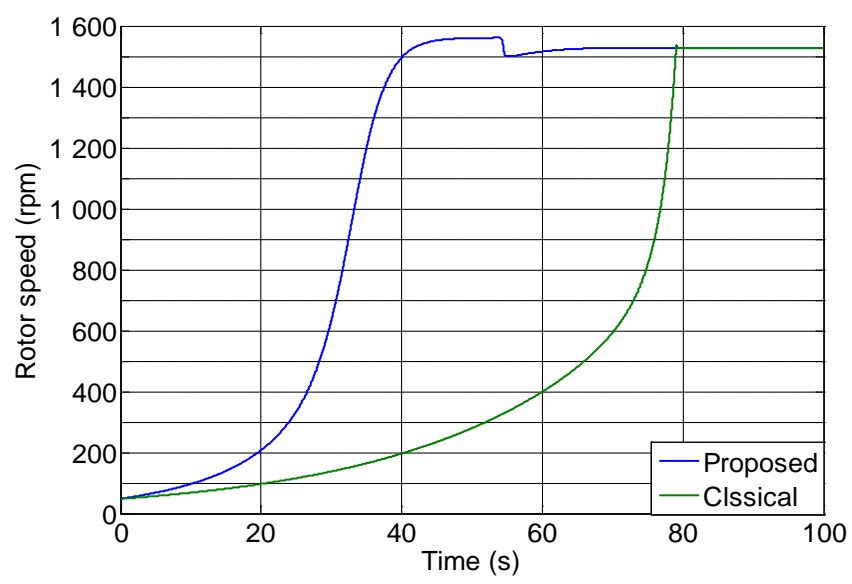

Figure 10. Evolution of WTG rotor speed.

Figure 11 with our soft starting/coupling procedure, when in classical strategies, it can reach 2 p.u. in Figure 12.

Figure 13 shows clearly steps of the proposed startin procedure. We can conclude that Interval I is the time needed for Step I, where rotor speed reachs steady state with a value just above the synchronism speed. Softstarting is completed during Interval II. Interval III is the time for mechanical contactors to be switched on, all the current generated by the SCIG is passing through contactors and soft starter is fully by-passed at the end of this step. Pitch angle is brought back to its value giving maximum mechanical power (decreased from $25^{\circ}$ to $2^{\circ}$ ) during the fourth interval. Finally, in the last interval, all power extracted from the wind is transferred to the grid by means of maximum mechanical torque applied on the rotor.

Also, the new procedure appears to be offering advantage in starting time, i.e. the WTG takes less time to be completely operative and injecting maximum power extracted from the wind. The proposed starting/coupling procedure offers approximatively $18 \%$ of time gain compared to the classical one.

\section{Conclusions}

An improved starting procedure of fixed speed, pitch controlled WTG was detailed in this paper. In fact, improvement is about limitation of inrush currents into the generator in the coupling moment and reducing starting time.

Controlling the starting procedure is to say controlling WT pitch angle. An algorithm was developed to determine the corresponding starting pitch angle whenever WTG is ready to run.

The WTG was modeled and simulated in both cases (improved and classic starting). The simulation results showed the efficiency of the proposed procedure. 


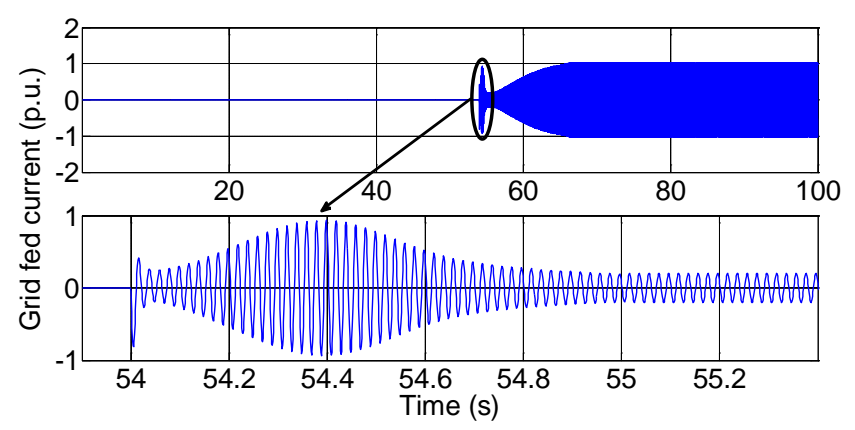

Figure 11. Evolution of the WTG's current in the proposed procedure.

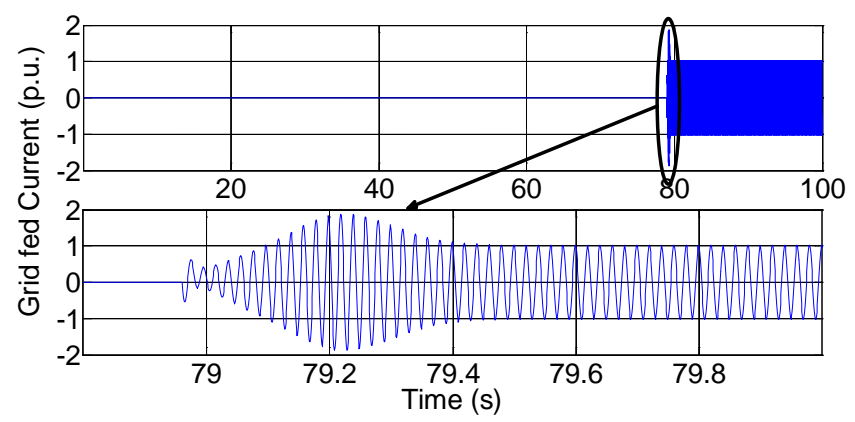

Figure 12. Evolution of the WTG's current in the classical procedure.

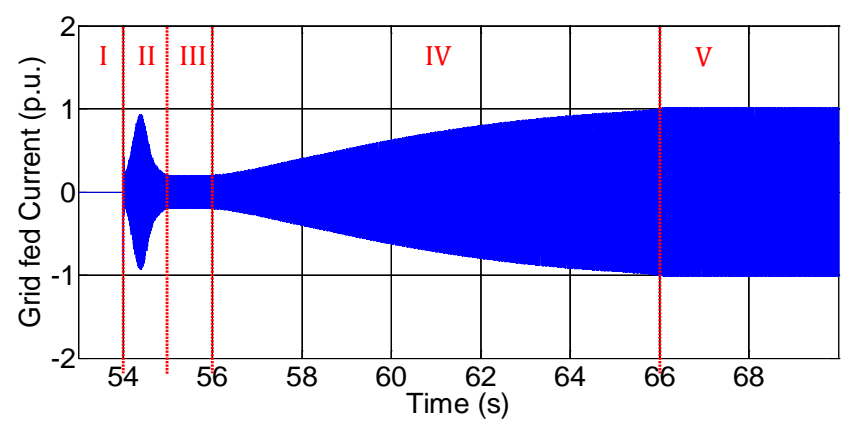

Figure 13. Proposed starting procedure steps.

\section{Acknowledgements}

Authors of this work would like to thank University of Sfax, Tunisia and especially the research unit CMERP for providing the facilities and research grant to achieve this research and great thanks to the reviewers for their valuable comments.

\section{References}

[1] Reza, N.H. and Farshad, D. (2013) Dynamic Maximum Available Power of Fixed-Speed Wind Turbine at Islanding Operation. Electrical Power and Energy Systems, 47, 147-156. http://dx.doi.org/10.1016/j.ijepes.2012.10.028

[2] Alkandari, A., Soliman, S. and Abdel-Rahman, M. (2011) Steady State Analysis of a Doubly Fed Induction Generator. Energy and Power Engineering, 3, 393-400. http://dx.doi.org/10.4236/epe.2011.34050

[3] Shi, L., Dai, S., Yao, L., Ni, Y. and Bazargan, M. (2010) Impact of Wind Farms of DFIG Type on Power System Transient Stability. Journal of Electromagnetic Analysis and Applications, 2, 475-481. http://dx.doi.org/10.4236/jemaa.2010.28063

[4] Simoes, M., Bose, B. and Spigel, R. (1997) Fuzzy Logic Based Intelligent Control of a Variable Speed Cage Induction 
Machine Wind Generation System. IEEE Transactions on Power Electronics, 12, 87-95. http://dx.doi.org/10.1109/63.554173

[5] Miller, A., Muljadi, E. and Zinger, D. (1997) A Variable Speed Wind Turbine Power Control. IEEE Transactions on Energy Conversion, 12, 181-186. http://dx.doi.org/10.1109/60.629701

[6] Benbouzid, M., Beltran, B., Amirat, Y., Yao, G., Han, J.G. and Mange, H. (2014) Second-Order Sliding Mode Control for DFIG-Based Wind Turbines Fault Ride-Through Capability Enhancement. ISA Transactions, 53, 827-833. http://dx.doi.org/10.1016/j.isatra.2014.01.006

[7] Saheb-Koussa, D., Haddadi, M., Belhamel, M., koussa, M. and noureddine, S. (2012) Modeling and Simulation of Windgenerator with Fixed Speed Wind Turbine under Matlab-Simulink. Energy Procedia, 18, 701-708. http://dx.doi.org/10.1016/j.egypro.2012.05.085

[8] Jansuya, P. and Kumsuwan, Y. (2013) Designe of MATLAB/Simulink Modeling of Fixed-Pitch Angel Wind Turbine Simulator. Energy Procedia, 34, 362-370. http://dx.doi.org/10.1016/j.egypro.2013.06.764

[9] Haque, M.H. (2014) Evaluation of Power Flow Solutions with Fixed Speed Wind Turbine Generating Systems. Energy Conversion and Management, 79, 511-518. http://dx.doi.org/10.1016/j.enconman.2013.12.049

[10] EL-Helw, H.M. and Tennakoon, S.B. (2008) Evaluation of the Suitability of a Fixed Speed Wind Turbine for Large Scale Wind Farms Considering the New UK Grid Code. Renewable Energy, 33, 1-12.

[11] Fernández, L.M., Saenz, J.R. and Jurado, F. (2006) Dynamic Models of Wind Farms with Fixed Speed Wind Turbines. Renewable Energy, 31, 1203-1230. http://dx.doi.org/10.1016/j.renene.2005.06.011

[12] Rodríguez, Á.G.G. (2006) Improvement of a Fixed-Speed Wind Turbine Soft-Starter Based on a Sliding-Mode Controller. Doctoral Thesis, University of Seville, Seville.

[13] Quinonez-Varela, G. and Cruden, A. (2008) Modelling and Validation of a Squirrel Cage Induction Generator Wind Turbine during Connection to the Local Grid. IET Generation Transmission Distribution, 2, 301-309.

[14] Domínguez-García, J.L., Gomis-Bellmunt, O., Trilla-Romero, L. and Junyent-Ferré, A. (2012) Indirect Vector Control of a Squirrel Cage Induction Generator Wind Turbine. Computers and Mathematics with Applications, 64, 102-114. http://dx.doi.org/10.1016/j.camwa.2012.01.021

[15] Li, H., Yang, C., Zhao, B., Wang, H.S. and Chen, Z. (2012) Aggregated Models and Transient Performances of a Mixed Wind Farm with Different Wind Turbine Generator Systems. Electric Power Systems Research, 92, 1-10. http://dx.doi.org/10.1016/j.epsr.2012.04.019

[16] Sulla, F., Svensson, J. and Samuelsson, O. (2011) Symmetrical and Unsymmetrical Short-Circuit Current of SquirrelCage and Doubly-Fed Induction Generators. Electric Power Systems Research, 81, 1610-1618. http://dx.doi.org/10.1016/j.epsr.2011.03.016

[17] Tunyasrirut, S., Wangsilabatra, B. and Suksri, T. (2010) Phase Control Thyristor Based Soft-Starter for a Grid Connected Induction Generator for Wind Turbine System. International Conference on Control, Automation and Systems 2010, Gyeonggi-do, 27-30 October 2010, 529-534.

[18] Lequeu, T. (2002) Annexe 08 — Gradateur à TRIAC, cours d'Electronique de Puissance [99DIV027].

[19] El Aimani, S. (2004) Modélisation de différents technologies d’éoliennes intégrées dans un réseau de moyenne tension. Doctoral Thesis, University of Lille 1 Science and Thechnology (USTL). 


\section{Nomenclature}

$\begin{array}{clcl}P: & \text { SCIG nominal power } & L_{s r}^{\prime}: & \text { Inductance of a rotor phase } \\ U: & \text { SCIG nominal voltage } & L_{m s}: & \text { Magnetizing inductance of stator phase } \\ f: & \text { Grid frequency } & L_{m r}: & L_{m s} \times M \\ p: & \text { Number of pole pairs } & M: & \text { Maximum coefficient of mutual induction } \\ J: & \text { Inertia of the SCIG } & \bar{i}_{\mathrm{sn}}: & \text { Stator current in the synchronous frame } \\ \bar{v}_{s n}: & \text { Stator voltage } & \bar{i}_{\mathrm{m}}^{\prime}: & \text { Rotor current in the synchronous frame } \\ \omega_{0}: & \text { Electric angular speed of the grid } & \bar{\Psi}_{s n}: & \text { Stator flux in the synchronous frame } \\ \omega_{r}: & \text { Electric angular speed of the SCIG } & \bar{\Psi}_{m}^{\prime}: & \text { Rotor flux in the synchronous frame } \\ L_{s}: & L_{s s}+L_{m s} & R_{s}: & \text { Resistance of a stator phase } \\ L_{r}: & L_{s r}^{\prime}+L_{m r} & R_{r}: & \text { Resistance of a rotor phase } \\ L_{s s}: & \text { Inductance of a stator phase } & & \end{array}$


Scientific Research Publishing (SCIRP) is one of the largest Open Access journal publishers. It is currently publishing more than 200 open access, online, peer-reviewed journals covering a wide range of academic disciplines. SCIRP serves the worldwide academic communities and contributes to the progress and application of science with its publication.

Other selected journals from SCIRP are listed as below. Submit your manuscript to us via either submit@scirp.org or Online Submission Portal.
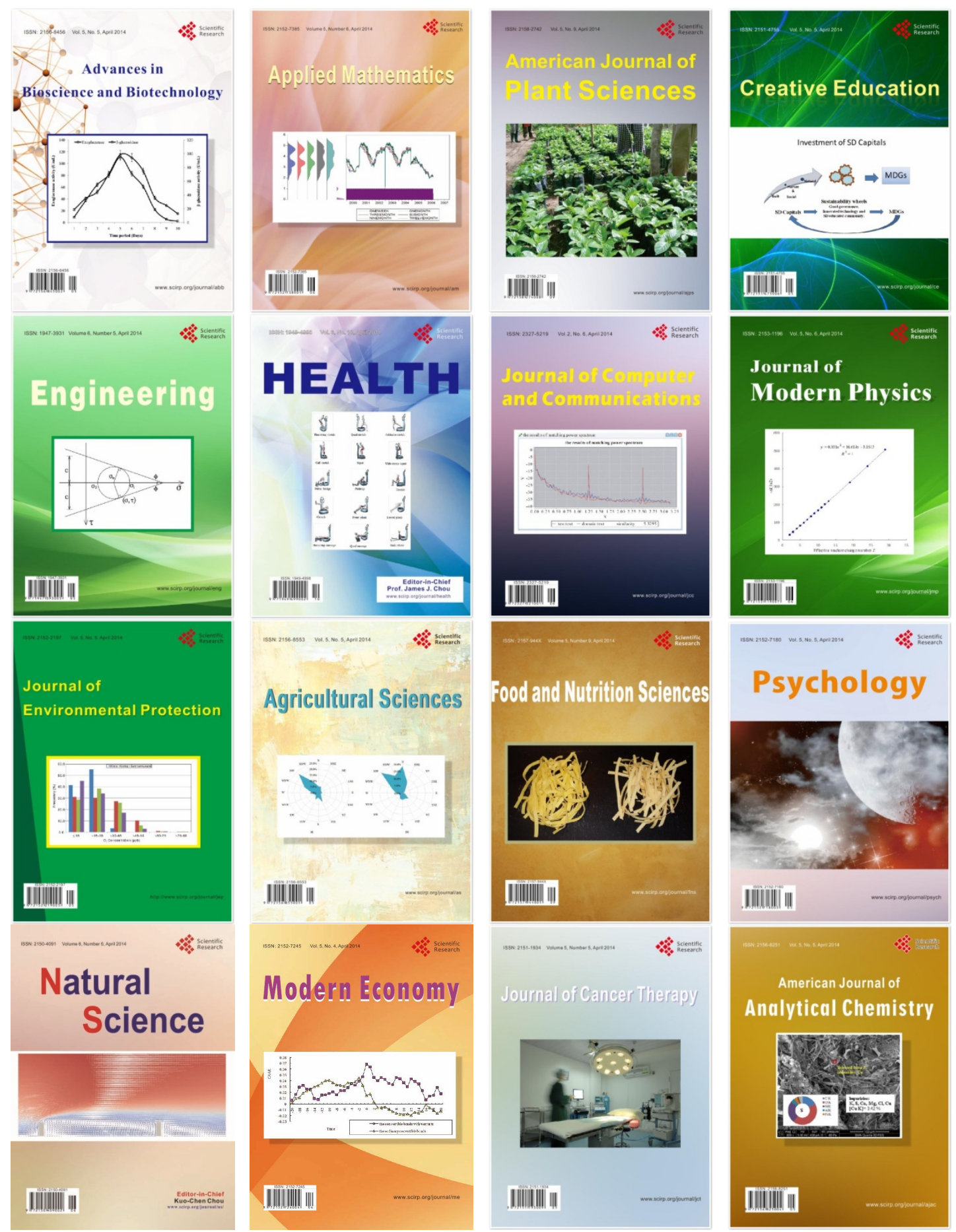